\title{
An Appraisal of Over-tourism on the Island of Crete, Greece
}

\author{
John Vourdoubas \\ Mediterranean Agronomic Institute of Chania, 73100, Chania, Crete, Greece \\ E-mail: vourdoubas@chania.teicrete.gr
}

Received: May 12, 2020 Accepted: June 17, $2020 \quad$ Published: June 20, 2020

doi:10.5296/ijgs.v4i1.17224 URL: https://doi.org/10.5296/ijgs.v4i1.17224

\begin{abstract}
Over-tourism is a multi-faced problem with severe economic, social and environmental consequences in tourist destinations. The island of Crete is an attractive and popular tourist destination in the Eastern Mediterranean basin and it is currently ranked among the ten most overcrowded EU tourism NUTS-2 regions. This fact could threaten and harm the fragile natural ecosystems in the island resulting in the decline of the prosperous tourism industry in the future. The aim of the current work is the estimation of various tourism indexes in the island of Crete which characterize over-tourism. Data regarding tourist arrivals and overnight stays in Crete in the previous years have been used for estimating the appropriate tourism indexes. Comparisons with other EU regions and with the average EU and global values have also been made. The possibility of creating a tourism observatory in Crete for tackling excess tourism has also been outlined. Our results indicate that Crete is categorized as an overcrowded tourism destination among EU regions while its tourism indexes are above the EU and global average. Cooperation among all stakeholders in the Cretan tourism industry is required in order to cope with over-tourism, shifting the local tourism industry towards a more sustainable and responsible model. The creation of a tourism observatory on the island with the participation of all tourism stakeholders is necessary. The observatory will assist in the development of the required policies offering guidance and advice for tackling excess tourism in Crete, avoiding economic, social and environmental degradation in the future.
\end{abstract}

Keywords: Crete, Greece, Impacts, Observatory, Over-tourism, Tourism indexes, Tourism destinations

\section{Introduction}

Over-tourism in popular tourist destinations is a problem raised in recent times causing many troubles in the tourism industry as well as in local communities. Global tourism, according to all forecasts, is going to increase in the future while the tourism industry in EU countries is one of the main pillars in their economies. Over-tourism is a multidimensional problem with 
multiple social, economic and environmental impacts. The island of Crete, Greece is a well-known tourist destination in the Eastern Mediterranean region with increasing tourist arrivals during the last decade. As an insular and coastal area, it is more fragile to excess tourism. Over-tourism in Crete could decrease the quality of the tourist product of the island causing undesired consequences for all tourism stakeholders. Additionally it could damage the fragile natural ecosystems in Crete, threatening their future sustainability. Therefore the estimation of various parameters and indexes which are related with over-tourism in Crete could help in the early design of the appropriate policies which could assist the local and regional authorities as well as the tourism industry to cope with this problem. Comparisons of the estimated Cretan indexes with the corresponding indexes in other EU regions could assist in mapping the current status of the tourism industry in the island. Taking into account that the hospitality industry in Crete currently accounts for approximately half of the island's GDP, the promotion of responsible and sustainable tourism could help all the tourism industry's stakeholders to avoid undesired consequences in the future.

\section{Literature survey}

\subsection{Over-tourism}

Szromek et al. (2019) have examined the perception of over-tourism from the perspective of different generations. The authors mentioned that the attitude of tourists to the problem of over-tourism may depend on their ages. They implemented an empirical study on a sample of 386 residents representing three different generations. Their results indicated different perceptions of over-tourism in different generations while they proposed the adoption of appropriate management practices promoting responsible and sustainable tourism. Peeters et al. (2018) have reported on the impacts and policy responses to over-tourism. The authors mentioned that over-tourism describes the situation in which the impact of tourism, at certain times and in certain locations, exceeds physical, ecological, social, economic, psychological and/or political capacity thresholds. Although a common set of indicators cannot be defined because of the complex causes and effects of over-tourism, they proposed some indicators which are the most relevant for over-tourism, as follows: a) Tourism density and tourism intensity, b) the share of Airbnb capacity and combined Airbnb and booking.com capacity, c) the share of tourism in the regional GDP, d) the travel intensity and e) closeness to airports and cruise ports, and UNESCO world heritage sites. Papathanassis (2017) has analyzed over-tourism and anti-tourist sentiments. The author mentioned that the externalities of tourism are increasingly visible over the last decade resulting in anti-tourism demonstrations in popular destinations. The author categorized the top 10 European tourism regions according to tourism density and tourism intensity including the South Aegean islands as well as Crete. He concluded that tourism policy makers should manage tourism destinations better and educate tourists. Milano et al. (2019) have studied over-tourism and tourism-phobia during the last four decades. The authors mentioned the antagonistic relationships between local residents and tourists, the tourist-carrying capacity in a region and the tourism area's life cycle. They stated that over-tourism as a rapidly evolving phenomenon has significant implications in policy and practices. Goodwin (2019) has reported on the causes and treatment of over-tourism. The author stated that over-tourism is the opposite of responsible tourism, having many causes including the low cost of travel and the desire to experience 
other people's places. However, he mentioned, there are limits to growth and we should make tourism better and avoid over-tourism. Elianson et al. (2018) have reported on over-tourism and on redirecting tourism consumption through social media. Over-tourism is a relatively new phenomenon where tourists and residents have the perception that there are too many tourists in a place, affecting the quality of life negatively as well as the visitor's experience. The authors stated that social media could be a useful channel where tourism stakeholders could express their views mitigating over-tourism in a destination and proposing better places to visit. Dodds et al. (2019) have reviewed the phenomena of over-tourism. The authors stated that over-tourism is a new term for an old problem which has resulted from a combination of factors which together have created a "perfect storm" of visitors to specific sites. They mentioned that its mitigation, reduction and prevention are necessary in order to avoid more severe problems in the future. Ciangra et al. (2017) have reported on the impacts of tourism. The authors stated that tourism has both positive and negative impacts which are economic, social, cultural and environmental. They mentioned that the environmental capacity of a destination should be assessed including the reception capacity and the support capacity. Simancas Cruz et al. (2019) have analyzed the accommodation density in coastal tourism areas of insular destinations from the perspective of over-tourism. The authors mentioned that tourist accommodation density is not the only parameter to assess the saturation of a coastal destination and it should be combined with tourist satisfaction levels. Both saturation and carrying capacity in a destination have a strict relation with over-tourism. Taiminen (2018) has studied the negative impacts of over-tourism in tourism destinations. The author mentioned that over-tourism causes environmental and socio-economic impacts which are almost similar in various tourist destinations. She stated that over-tourism is going to increase steadily and various measures should be taken to avoid future deterioration. Perkumiene et al. (2019) have analyzed the rights of tourists to travel and the rights of residents in destinations with heavy tourist loads. The authors mentioned that tourists have the right to travel and the local residents have the right to avoid deterioration in the quality of their lives. They stated that the problem of over-tourism should be solved by developing sustainable tourism, balancing equally between the rights of the tourists and the rights of the residents. Capocchi et al. (2019) have reviewed the implications and future perspectives of over-tourism. The authors mentioned that the problems caused in some destinations by the increasing growth of tourism created the multi-faceted issue of over-tourism. They stated that in the near future over-tourism will increase the pressures related with environmental degradation and climate change. Additionally, they added it should be necessary in the future to educate tourists. Navarro Jurado et al. (2012) have developed a methodology for assessing the carrying capacity of tourist destinations. The authors proposed multi-criteria analysis using synthetic indicators for assessing the limits to growth in a tourist destination. The indicators used were categorized in three groups including social, economic and environmental indicators setting a minimum and a maximum value for each one. Avond et al. (2019) have studied the causes of over-tourism. The authors mentioned that although tourism is not an issue, over-tourism is inevitable in the future causing negative consequences. In order to tackle over-tourism in various destinations, a joint effort from all stakeholders is required. Tour operators should rethink how to promote popular touristic spots and tourists 
should be educated to be responsible, while local authorities in popular destinations should take corrective actions to manage visitors in a sustainable way. Navarro Jurado et al. (2013) have studied the social carrying capacity in a coastal tourist destination in Costa Del Sol, Spain. The authors implemented empirical surveys with questionnaires investigating the perception of tourists concerning overcrowding and their predisposition to leave. Their findings indicated that only $20 \%$ of tourists, who were mature, better educated and had a higher socioeconomic status, were more sensitive to overcrowding. They also mentioned that a low level of authenticity and a high level of noise were the most important factors influencing the social carrying capacity of the destination.

\subsection{Over-tourism in Cities}

Koens et al. (2018) have investigated the impacts of tourism in a city context. The authors mentioned that the concept of over-tourism has been recently over-discussed while it remains open to many interpretations. They stated that the concept is multidimensional and complex while its impacts are not only negative and they should be further studied and better understood. Annar et al. (2019) have studied the impacts of over-tourism towards the local community in a heritage city. The authors mentioned that over-tourism gave many economic opportunities to local residents. However, various negative impacts were also identified, concluding that over-tourism has both positive and negative impacts. Hospers (2019) has reported on the challenges of over-tourism in European cities. The author mentioned that over-tourism is created by both the increase in global travelling and the difficulties of local stakeholders in coping with it. He mentioned that tourism is beneficial for European cities since it is an important source of business activity and income. Over-tourism though is a cause of economic problems related with the "tragedy of the commons", to adverse social effects as well as negative physical effects on a city. Poczta et al. (2020) have assessed the effect of medium-scale sporting events on the city's residents with reference to the city of Poznan, Poland. The authors implemented an empirical survey questioning 774 participants regarding their dissatisfaction from the organization of two athletic events in their city. Their results indicated that the city's residents were more dissatisfied from the medium-scale "mass event" compared with the second more "elite-oriented" sport event. Martin Martin et al. (2018) have analyzed the factors behind the citizens' attitudes of rejection towards tourism in destinations characterized by over-tourism like Barcelona. The authors mentioned the city of Barcelona where the tourism model has changed, characterized by the increasing offer of both hotel rooms and rooms outside hotels and the rise of low-cost tourism. This has resulted in the rejection of tourism, particularly from the most vulnerable population groups who perceive rises in properties prices and in the cost of living due to over-tourism in the city. Zemla (2020) has analyzed the reasons and consequences of over-tourism in contemporary cities. The author mentioned that extensive research on over-tourism has been implemented in recent years. Many reasons for this phenomenon have been highlighted by various researchers, including the increasing number of tourists globally, the high availability of cheap flights and the development and use of information technologies in tourism. The author stated that an additional reason for over-tourism in cities is the shift from the $3 \mathrm{~S}$ (sea, sun and sand) model to the 3E (education, experience and entertainment) model. Massiani et al. (2012) have investigated tourism management in Venice, Italy, a popular tourist destination. The 
authors reviewed the use of tourism capacity for the management of tourist flows in Venice, stating that this concept has controversial aspects. They mentioned that the management of tourist flows usually has strong negative outcomes for a limited number of stakeholders while it has limited/indirect benefits for a large number of them. Maggi et al. (2010) have estimated the carrying capacity of a coastal city located in South Italy. The authors mentioned that estimation of the carrying capacity in a tourism destination is necessary in order to know the maximum limits of tourism development. They also stated that tourism-carrying capacity includes three dimensions: the physical-ecological, the socio-demographic and the political-economic.

\subsection{Over-tourism in Greece}

Sakellariou et al. (2016) have studied the environmental pressures of tourism on coastal and tourism zones in Greece. The authors stated that there are many environmental problems caused by the intensive tourist development including depletion of natural resources, extensive pollution and coastal erosion. They mentioned that appropriate measures should be taken in order to protect these precious and vulnerable resources. Sarantakou et al. (2019) have studied the impacts of non-conventional tourist accommodations and over-tourism on landscape with reference to the island of Santorini, Greece. The authors mentioned that the increase of non-institutionalized forms of tourist accommodation exacerbates over-tourism, resulting in undesired impacts on land uses and landscape. They stated that in Santorini, the exploitation of small-scale land ownership and second residence development intensifies over-tourism, resulting in unwanted environmental deterioration related with spatial planning and landscape management. Angelakis (2018) has reported on the tourism industry in Crete, mentioning that over 5 mil tourists arrive annually to the island. Among them, approximately 2 mil arrive in Western Crete. He also stated that the share of tourism in the Cretan GDP is at $47 \%$. The new developments of the Cretan tourism industry have been presented by the Region of Crete, 2017. The report mentioned that in 2016, the total tourist arrivals by air and sea to the island were 4,902,194. Vourdoubas (2020) has estimated the carbon intensity of the tourism industry in Crete. The author stated that its carbon intensity is in the same range of values reported in other EU countries, while most carbon emissions are due to air transportation. Tourism density and tourism intensity in the most popular and overcrowded European tourism regions are presented in Table 1.

Table 1. Tourism density and intensity in the most popular European tourism destinations

\begin{tabular}{lll}
\hline Region/country & $\begin{array}{l}\text { Tourism density (bed-nights } \\
\text { per } \mathrm{Km}^{2} \text { ) }\end{array}$ & $\begin{array}{l}\text { Tourism intensity (bed-nights } \\
\text { per inhabitant) }\end{array}$ \\
\cline { 2 - 3 } & & 69.8 \\
\hline South Aegean islands & 4,463 & 36.8 \\
Crete & 3,013 & 9.1 \\
Greece & 771 & 58 \\
Balearic islands & 14,007 & 44.2 \\
Canary islands & 13,791 & \\
\hline
\end{tabular}




\begin{tabular}{lll} 
Spain & 899 & 9.1 \\
Bolzano & 4,233 & 56.8 \\
Trentino & 2,727 & 29.9 \\
Italy & 1,333 & 6.5 \\
Corsica & 1,649 & 29.8 \\
France & 639 & 6.2 \\
Algarve & 4,189 & 42.7 \\
Portugal & 715 & 5.7 \\
Adriatic Croatia & N/A & 48.6 \\
Croatia & 887 & 16.9 \\
\hline
\end{tabular}

Source: Papathanassis, 2017, Data for years 2015/2016

The aims of the current study are:

a) To estimate various indicators for appraising over-tourism in the island of Crete, Greece,

b) To compare some Cretan indicators regarding over-tourism with the same indicators in other EU regions, and the global values, and

c) To examine the possibility of creating a tourism observatory on the island of Crete, Greece

Limitations in the current study are related with the accuracy of the data used, taking into account that the number of tourists' overnight stays in Crete could have been underestimated. Various data used in estimations have also been taken in different years due to the lack of the required data in the same year. The methodology used includes a literature survey followed by the presentation of the causes and consequences of over-tourism in Crete. In the next section, various indexes for appraising over-tourism in Crete have been estimated and compared with the corresponding indexes in other regions, as well as with EU and global values. The possibility of creating a tourism observatory in Crete is examined, while in the last part of the text, a discussion of the findings is presented, followed by the conclusions drawn and proposals for further research.

\section{Causes and consequences of over-tourism}

Over-tourism describes the situation in which the impact of tourism, at certain times and in certain locations, exceeds physical, ecological, social, economic, psychological, and/or political capacity thresholds (Peeters et al., 2018). Over-tourism is a recent multi-faceted phenomenon having many causes and many consequences. It is believed that the most vulnerable destinations are islands and coastal areas. The main causes include the increasing number of tourists globally, the cheap flights allowing long distance travelling combined with low cost accommodation, the increasing use of information technologies in the tourist industry, the strong branding of various tourist destinations, the promotion of the tourism industry from local and regional authorities in order to increase the local income, the development of the sharing economy, etc. Over-tourism also has multiple consequences in all stakeholders involved. It is perceived differently by the tourists and the residents. Many tourists, particularly in the older age groups, are not pleased with overcrowding and excess 
noise at the destination. The undesired consequences at the destination are social, environmental and economic. Social impacts are related with the discomfort of local residents with overcrowding due to large numbers of visitors, traffic congestion and the noise created in their cities and neighborhoods. Many of them believe that the quality of their lives is detetoriated. Recently the growth of the sharing economy has significantly raised the rental costs of dwellings in tourism-dominated territories. Additionally the prices of foodstuff are usually increased in many destinations affecting the local residents negatively. Environmental impacts are related with the excess wastes produced by a large number of tourists in a destination and the low capacity of the existing infrastructure to handle them. High numbers of visitors accumulating in environmentally sensitive and protected areas is damaging the local fragile ecosystems. Over-tourism is creating economic damage in other economic sectors, limiting the availability of the local workforce. However there are important economic benefits due to excess tourism in various destinations. Tourism growth in territories with limited other resources promotes local investments and creates new jobs and wealth. New business enterprises are created in destinations offering various types of services to visitors. Locally produced foodstuff is feeding tourists, promoting local gastronomy, supporting local agriculture and increasing the nexus between agriculture and tourism. Due to the abovementioned benefits, local stakeholders support the tourism industry. However, in every tourism destination, there are limits to growth and when the carrying capacity of the destination is exceeded, the consequences could be destructive. Coping with over-tourism to avoid degradation of the tourism product requires smooth cooperation of all stakeholders involved in the tourism chain. Transition from over-tourism to sustainable or responsible tourism requires the tourists' education, better management in tourist destinations and probably the de-branding of the popular tourist areas. Over-tourism results in disruption of the balance between the rights of tourists to travel and visit various destinations and the rights of local residents to avoid deterioration in the quality of their lives and to live in an unspoiled environment.

\section{Estimation of various indicators for over-tourism in Crete}

Various indicators for estimating over-tourism in a destination have been proposed, including:

1) Tourism density and intensity which are considered the most important for over-tourism,

2) Growth of bed-nights (when combined with intensity),

3) Share of Airbnb accommodation,

4) Share of tourism contribution to GDP,

5) Air travel intensity, and

6) Closeness to airports, cruise ports and World Heritage Sites.

However there is no commonly agreed set of indicators to clearly qualify and quantify over-tourism in a destination.

\subsection{Tourism Density}

The tourism density in Crete is estimated taking into account that during 2017, 24,516,000 tourist bed-nights were recorded in the island while its area is $8,332 \mathrm{Km}^{2}$. Therefore the tourism density in Crete is 2,941 bed-nights per $\mathrm{Km}^{2}$. The tourism density in Greece has been estimated at 902 bed-nights per $\mathrm{Km}^{2}$. 


\subsection{Tourism Intensity}

The tourism intensity in Crete is estimated taking into account that its population totals 634,930 inhabitants. Therefore the tourism density in the island is 38.6 bed-nights per inhabitant. The tourism density in Greece has been estimated at 11.1 bed-nights per inhabitant.

\subsection{Air Travel Intensity}

The air travel intensity in Crete is estimated taking into account that in 2017, flight passengers in the island were 4,355,370. Therefore the air travel intensity in Crete is 0.178 air-passengers per bed-nights.

\subsection{Share of Tourism Contribution to GDP}

The share of tourism contribution to Cretan GDP has been estimated at 47\% (Angelakis, 2018). The share of tourism in other Greek regions dominated by tourism is $73 \%$ for the Ionian islands and 93\% for the South Aegean islands.

\subsection{Airbnb Accommodation}

During the recent years Airbnb accommodation has been expanded rapidly in Greece, particularly in regions dominated by tourism. These tourism facilities are growing in an uncontrolled way without regulations, creating unfair competition in other tourism enterprises. Airbnb accommodations located in the six most popular Greek regions are presented in Table 2. These accommodations correspond to approximately $87.9 \%$ of the total Airbnb facilities operating in the country.

Table 2. Airbnb accommodations operating in six Greek regions

\begin{tabular}{lll}
\hline Region (NUTS-3) & Number of accommodations & Accommodations per capita \\
\cline { 3 - 3 } & & \\
\hline Crete & 21,811 & 0.034 \\
Ionian islands & 13,232 & 0.065 \\
South Aegean islands & 25,730 & 0.083 \\
Attica & 31,184 & 0.008 \\
Central Macedonia & 13,544 & 0.007 \\
Peloponnese & 6,474 & 0.006
\end{tabular}

${ }^{1}$ Source: Airbnb in Greece, 2019, Data: June, 2018

\subsection{Airport and Cruise Port Availability in Crete}

There are two main airports in Crete, located in the Eastern and Western part of the island with heavy tourist loads, and one minor airport in the Eastern part. The two main airports are located at a distance of less than $15 \mathrm{Km}$ from the two largest cities in Crete: Chania and Heraklion. There also two main sea ports used as cruise ports in the island, located less than 6 $\mathrm{Km}$ from the two large cities, which are visited by tourists during their stay on the island. 


\section{Mll Macrothink}

International Journal of Global Sustainability

ISSN 1937-7924 2020, Vol. 4, No. 1

\section{Comparison of Cretan Indicators of Over-Tourism With Indicators in Other Regions}

The estimation of tourism density and intensity in Greek regions has been made and compared with the European and global values. The air transport intensity in Crete is also compared with the corresponding EU values.

\subsection{Comparison of Tourism Density and Intensity of Crete With Other Greek regions}

Cretan indicators of over-tourism are compared with the same indicators in other Greek regions. Tourism density and tourism intensity are presented in Table 3. The three Greek regions with the higher tourism densities and intensities are Crete, the Ionian islands and the South Aegean islands.

Table 3. Tourism density and tourism intensity in Greek regions and the country

\begin{tabular}{lll}
\hline Region (NUTS-2) & $\begin{array}{l}\text { Tourism } \\
\text { (bed-nights per } \mathrm{Km}^{2} \text { ) }\end{array}$ & $\begin{array}{l}\text { Tourism } \\
\text { (bed-nights per inhabitant) }\end{array}$ \\
\cline { 2 - 3 } & & $\begin{array}{r}\text { intensity } \\
\text { Crete }\end{array}$ \\
Ionian islands & 4,941 & 38.60 \\
South Aegean islands & 4,059 & 48.96 \\
Attica & 2,329 & 69.43 \\
Central Macedonia & 519 & 2.37 \\
Peloponnese & 157 & 5.18 \\
Thessaly & 162 & 2.92 \\
Eastern Macedonia-Thrace & 149 & 3.10 \\
Western Greece & 173 & 3.47 \\
Central Greece & 116 & 3.00 \\
North Aegean islands & 456 & 3.29 \\
Epirus & 125 & 7.92 \\
Western Macedonia & 31 & 3.43 \\
Greece (NUTS-1) & 902 & 1.04 \\
& & 11.1
\end{tabular}

Source: Own estimations, Tourism in Greece, 2018.

\subsection{Comparison of Tourism Density and Intensity of Crete with EU Indicators}

Tourism density and intensity in Crete, as well as in the Ionian islands and the South Aegean islands, is compared with the average, minimum and maximum values reported in the EU, and with the average global values. The results are presented in Table 4. 


\section{Macrothink}

International Journal of Global Sustainability

ISSN 1937-7924 2020, Vol. 4, No. 1

Table 4. Tourism density and intensity in Greek regions, in Greece, in the EU-28 and globally

\begin{tabular}{|c|c|c|}
\hline Region/country & $\begin{array}{l}\text { Tourism density } \\
\text { (bed-nights per } \mathrm{Km}^{2} \text { ) }\end{array}$ & $\begin{array}{l}\text { Tourism intensity } \\
\text { (bed-nights per inhabitant) }\end{array}$ \\
\hline Crete (NUTS-2) & 2,941 & 38.6 \\
\hline Ionian islands (NUTS-2) & 4,327 & 48.96 \\
\hline South Aegean islands (NUTS-2) & 4,059 & 69.43 \\
\hline Greece (NUTS-1) & 902 & 11.1 \\
\hline Average EU-28 ${ }^{1}$ & 629.3 & 5.77 \\
\hline Minimum EU-28 ${ }^{1}$ & 26.1 & 0.34 \\
\hline Maximum EU-28 ${ }^{1}$ & 37,300 & 70.73 \\
\hline Average global & 181.8 & 3.31 \\
\hline
\end{tabular}

Source: Own estimations, Peeters et al, 2018, ${ }^{1}$ Countries and NUTS-2 regions, domestic and international tourists in 2015/2016

Table 4 indicates that tourism density and intensity in Crete, the Ionian islands and the South Aegean islands are significantly higher than the average values reported for the EU-28 as well as the global average value. Tourism intensities in the South Aegean islands and the Ionian islands are approaching the maximum value reported in the EU-28. Tourism density and intensity in Greece are exceeding the average EU-28 values.

\subsection{Comparison of Air Travel Intensity of Crete With the Corresponding EU Values}

It has been reported by Peeters et al. (2018) that the average air travel intensity for EU NUTS-2 destinations without over-tourism is at 0.797 air-passengers per bed-nights, while for destinations with over-tourism it is at 0.827 air-passengers per bed-nights. The calculated air travel intensity for Crete is at 0.178 air-passengers per bed-nights which is significantly lower than the average value reported for EU destinations without over-tourism.

5.4 Comparison of Tourism Density and Intensity in Crete With Tourism Density and Intensity in the Island of Santorini

Santorini (NUTS-3) is a famous volcanic Greek island located in the Aegean Archipelago which is suffering from over-tourism. Tourist overnight stays in Santorini have been estimated at 5,500,000 while its area is $76 \mathrm{Km}^{2}$, having 15,500 inhabitants (Peeters et al., 2018). Tourism density in Santorini is estimated at 72,368 bed-nights per $\mathrm{Km}^{2}$ compared with 2,941 bed-nights per $\mathrm{Km}^{2}$ for Crete. Tourism intensity in Santorini is at 354 bed-nights per inhabitant compared with 38.6 bed-nights per inhabitant for Crete. Over-tourism in Santorini has already created many unwanted social and environmental consequences, threatening the prosperous tourism industry in the island.

\section{Possibility of Creating a Tourism Observatory in Crete}

Transition to sustainable and responsible tourism requires the smooth cooperation of all stakeholders in the tourism industry in order to design and promote the required policies. 


\section{MInstitute Macrothin}

Stakeholders include local and regional authorities, local and international tour operators, enterprises which offer services to tourists, as well as local residents and tourists. Various stakeholders are affected differently by the required policies and the compromise among different interests is not always easy. In order to be able to assess the impacts of excess tourism in the region of Crete and to design the optimum policies for its mitigation, it is necessary to create a tourism observatory which will record annually all the required data and information concerning the tourism industry in Crete. Additionally the sentiments of the local residents will be recorded and their attitudes regarding incoming tourism should be taken into account in order to design the proper measures and policies tackling excess tourism and its undesired consequences. The tourism observatory in Crete could be established as a not-for-profit organization and it should record:

a) Data which are necessary to estimate various indexes for assessing over-tourism,

b) The positive and negative economic impacts due to tourism in Crete,

c) The positive and negative social impacts due to tourism in Crete, and

d) The negative environmental impacts, particularly in the fragile natural ecosystems of the island.

Participants in this observatory should include:

1) The region of Crete,

2) The Cretan municipalities which are hosting a large number of tourists annually,

3) The chambers of commerce in the island, and

4) The Hoteliers Associations in Crete

The Cretan tourism observatory should be financed by its members and it could be partly subsidized by EU structural funds. Apart from gathering the necessary data from the tourism industry in Crete, it should examine its economic, social and environmental impacts in the island which are both positive and negative. Additionally it will advise the public authorities regarding the necessary measures and policies for mitigating excess tourism and over-tourism as well as the required policies for the transition to sustainable and responsible tourism. Taking into account the impacts of the tourism industry to climate change, which is one of the most important global environmental problems, the tourism observatory should also consult tourism stakeholders in mitigating it.

\section{Discussion}

The estimated tourism density and tourism intensity in Crete is similar to the values reported so far (Papathannnasis, 2017; Peeters et al., 2018) while they are among the highest compared with other European regions. The island of Crete together with the Ionian islands and the South Aegean islands are the three most popular tourism destinations in Greece which during the summer are over-crowded. The present study gives an insight regarding over-tourism in Crete which is an insular destination with many coastal touristic spots and fragile natural ecosystems. Although the tourism industry is very important for the regional economy and prosperity, there is currently a lack of systematic recording of tourism inflows in Crete at regular intervals which could help detect and tackle over-tourism. Various commonly agreed tourism indicators should be estimated and analyzed by all tourism 
stakeholders in order to design and promote the necessary actions and policies mitigating over-tourism. Since the tourism industry in the island has both positive and negative impacts in many stakeholders, it will not be easy to find a compromise among them to cope with the undesired and harmful consequences. In any case, the transition from over-tourism to sustainable and responsible tourism in Crete is the only viable option for the future. The vulnerability of the insular and coastal ecosystems in the Mediterranean basin necessitates the adoption of better management practices of the tourism industry, avoiding undesired economic, social and environmental impacts. The current study assesses various recent tourism indexes in Crete highlighting the problem of over-tourism in the island compared with other Greek and European destinations. It also highlights the necessity and the importance of creating a tourism observatory in the island in order to assess the tourism inflows in Crete and the undesired consequences of tourism industry.

\section{Conclusions}

The island of Crete is among the three most popular tourist destinations in Greece and among the ten most popular in the EU, attracting many visitors per year. Its tourism industry has a share of approximately $47 \%$ in the island's GDP. The tourist density in Crete has been estimated, for 2017 , at 2,941 bed-nights per $\mathrm{Km}^{2}$ while its tourism intensity is at 38.6 bed-nights per inhabitant compared with 902 bed-nights per $\mathrm{Km}^{2}$ and 11.1 bed-nights per inhabitant correspondingly in Greece. These values are almost similar with those reported in other studies for previous years and well above the average EU and global values. However, Crete is an insular tourist destination with many coastal tourism spots, and therefore it is vulnerable to over-tourism. Its impacts on the fragile natural ecosystems could be catastrophic. Additionally, excess tourism has undesired social consequences to local residents. Tackling excess tourism and moving towards responsible tourism requires smooth cooperation among all stakeholders of the tourism industry in order to promote the appropriate policies for that. The creation of a tourism observatory in Crete which will gather and process all the required data and information regarding the local tourism industry would be helpful and useful. It could offer advice and guidance for all tourism stakeholders regarding the status of the industry and avoiding its harmful consequences. Additionally, it will assist in the creation of the appropriate policies and measures in order to achieve the transition from excess tourism into sustainable and responsible tourism in the island. Further research should be focused on estimating various additional parameters related with over-tourism in Crete during the recent years. A study on the social and environmental carrying capacity of tourism in Crete indicating the limits of its growth should be implemented. A preliminary study regarding the creation of a tourism observatory in the island with the participation of all stakeholders should also be a priority in further research.

\section{Acknowledgements}

I would like to thank my colleagues at MAICh for supporting the research, and Mrs. Maria Verivaki who has read the manuscript and has made positive comments.

\section{References}

Angelakis, G. (2018). Tourism observatory: A joint effort for an innovative entrepreneurship in Western Crete, [Power Point slides]. Retrieved at 4/5/2020 from 
http://chania-cci.gr/wp-content/uploads/2017/10/angelakis.pdf

Anuar, A. N. A., Ridzuan, F. H., Jaini, N., Sulaiman, F. C., \& Hashim, N. I. (2019). The Impact of Over-tourism towards Local Community in Heritage City. Journal of Tourism Hospitality, 8, 406.

Airbnb in Greece, (In Greek), (2019). Available https://www.alfavita.gr/koinonia/284806_ereyna-airbnb-stin-ellada-se-arithmoys.

Avond, G., Bacari, C., Limea, I., Seraphin, H., Gowreesunkar, V., \& Mhanna, R. (2019). "Over-tourism: a result of the Janus-faced character of the tourism industry". Worldwide Hospitality and Tourism Themes, 11(5), 552-565. https://doi.org/10.1108/WHATT-06-2019 $-003$

Building regional actions for new development in Tourism, Region of Crete. (2017). Regional survey, BRANDTOUR, INTERREG Europe.

Capocchi, A., Vallone, C., Pierotti, M., \& Amaduzzi, A. (2019). Over-tourism: A literature review to assess implications and future perspectives. Sustainability, 11, 3303. https://doi.org/10.3390/su11123303

Cianga, N., \& Sorocovchi, V. (2017). The impact of tourism activities. A point of view. Riscurisi Catastrofe, XVI, 20, 1/2017, 25-40. https://doi.org/10.24193/RCJ2017_02

Dodds, R., \& Butler, R. (2019). The phenomena of over-tourism: a review. International Journal of Tourism Cities. https://doi.org/10.1108/IJTC-06-2019-0090

Elianson, E., \& Velasco, K. (2018). Coping with over-tourism: Redirecting tourism consumption through social media and the internet, M.Sc. thesis, School of Business, Economics and Law, Gothenburg, Sweden.

Goodwin, V. H. (2019). Over-tourism: Causes, symptoms and treatment. Tourismus Wissen, 110-114.

Hospers, G-J. (2019). Over-tourism in European cities: From challenges to coping strategies. Focus, CESifo Forum, 3/2019, 20, 20-24.

Koens, K., Postma, A., \& Papp, B. (2018). Is over-tourism overused? Understanding the impact of tourism in a city context. Sustainability, 10, 4384. https://doi.org/10.3390/ su10124384

Maggi, E. F., \& Lorenzo, F. (2010). The carrying capacity of a tourist destination. The case of a coastal Italian city, 50th Congress of the European Regional Science Association: "Sustainable Regional Growth and Development in the Creative Knowledge Economy", 19-23 August 2010, Jönköping, Sweden, European Regional Science Association (ERSA), Louvain-la-Neuve. (online).

Martin Martin, J. M., Guaita Martinez, J. M., \& Salinas Fernandez, J. M. (2018). An analysis of the factors behind the citizen's attitudes of rejection towards tourism in a context of over-tourism and economic dependence on this activity. Sustainability, 10, 2851. https://doi.org/10.3390/su10082851

Massiani, J., \& Santoro, G. (2012). The relevance of the concept of capacity for the management of a tourist destination: Theory and application to tourism management in Venice. RivistaItaliana de Economia Demografia\&Statistica, LXVI (2), 141-156. 
Milano, C., Novelli, M., \& Cheer, J. M. (2019). Over-tourism and Tourism-phobia: A Journey Through Four Decades of Tourism Development, Planning and Local Concerns. Tourism Planning \& Development, 16(4), 353-357. https://doi.org/10.1080/21568316.2019.1599604

Navarro Jurado, E., Tejada Tejada, M., Almeida García, F., Cabello González, J., Cortés Macías, R., Delgado Peña, J., ... Solís Becerra, F. (2012). Carrying capacity assessment for tourist destinations. Methodology for the creation of synthetic indicators applied in a coastal area. Tourism Management, 33, 1337-1346. https://doi.org/10.1016/j.tourman.2011.12.017

Navarro Jurado, E., Damian, I. M., \& Fernandez-Morales, A. (2013). Carrying capacity model applied in coastal destinations. Annals of Tourism Research, 43, 1-19. https://doi.org/10.1016/j.annals.2013.03.005

Papathanassis, A. (2017). Over-tourism and anti-tourist sentiment: An exploratory Analysis and Discussion, "Ovidius". University Annals, Economic Science Series, Vol XVII (2), 288-293.

Peeters, P., Gössling, S., Klijs, J., Milano, C., Novelli, M., Dijkmans, C., ... Postma, A., (2018). Research for TRAN Committee - Over-tourism: impact and possible policy responses, European Parliament, Policy Department for Structural and Cohesion Policies, Brussels.

Perkumiene, D., \& Pranskumiene, R. (2019). Over-tourism: Between the right to travel and resident's rights. Sustainability, 11, 2138.https://doi.org/10.3390/su11072138

Poczta, J., Dabrowska, A., Kazimierczak, M., Gravelle, F., \& Malchrowicz-Mosko, E. (2020). Over-tourism and medium scale sporting events organizations - the perception of negative externalities by host residents. Sustainability, 12, 2827. https://doi.org/10.3390/su12072827

Sakellariou, St., Samara, F., Tampekis, St., Sfoungaris, I., \& Christopoulou, O. (2016). The environmental pressures and perspectives of tourism in coastal and insular zone. The case of Greece. Nature, Environment and Pollution Technology, 15(8), 1009-1020.

Sarantakou, E., \& Terkenli, T. S. (2019). Non-Institutionalized forms of tourism accommodation and over-tourism impacts on the landscape: The case of Santorini, Greece. Tourism Planning and Development. https://doi.org/10.1080/21568316.2019.1569122

Simancas Cruz, M., \& Penarrubia Zaragoza, M. P. (2019). Analysis of the accommodation density in coastal tourism areas of insular destinations from the perspective of over-tourism. Sustainability, 11, 3031. https://doi.org/10.3390/su11113031

Szromek, A. R., Hysa, B., \& Karasek, A. (2019). The perception of over-tourism from the perspective of different generations. Sustainability, 11, 7151. https://doi.org/10.3390 /su11247151

Taiminen, S. (2018). The negative impacts of over-tourism on tourism destinations from environmental and socio-economic perspectives.

Tourism in Greece. (2018). Greek Statistics Organization (In Greek).

Vourdoubas, J. (2020). The tourism industry in the island of Crete, Greece: Is it carbon-intensive? Sustainability in Environment, 5(1), 23-36. https://doi.org/10.22158/se. v5n $1 \mathrm{p} 23$

Zemla, M. (2020). Reasons and consequences of over-tourism in contemporary cities - 


\section{Macrothink}

International Journal of Global Sustainability

ISSN 1937-7924 2020, Vol. 4, No. 1

$\begin{array}{llllll}\text { knowledge gaps and future research. Sustainability, } & 12, & 1729 .\end{array}$ https://doi.org/10.3390/su12051729

\section{Copyright Disclaimer}

Copyright for this article is retained by the author(s), with first publication rights granted to the journal.

This is an open-access article distributed under the terms and conditions of the Creative Commons Attribution license (http://creativecommons.org/licenses/by/4.0/). 